\title{
Video Article \\ A Noninvasive Hair Sampling Technique to Obtain High Quality DNA from Elusive Small Mammals
}

\author{
Philippe Henry ${ }^{1}$, Alison Henry ${ }^{1}$, Michael A. Russello ${ }^{1}$ \\ ${ }^{1}$ Department of Biology and Centre for Species at Risk and Habitat Studies,, University of British Columbia, Okanagan Campus
}

Correspondence to: Philippe Henry at phenry@interchange.ubc.ca

URL: https://www.jove.com/video/2791

DOI: doi:10.3791/2791

Keywords: Genetics, Issue 49, Conservation genetics, noninvasive genetic sampling, Hair snares, Microsatellites, AFLPs, American pika, Ochotona princeps

Date Published: $3 / 13 / 2011$

Citation: Henry, P., Henry, A., Russello, M.A. A Noninvasive Hair Sampling Technique to Obtain High Quality DNA from Elusive Small Mammals. J. Vis. Exp. (49), e2791, doi:10.3791/2791 (2011).

\section{Abstract}

Noninvasive genetic sampling approaches are becoming increasingly important to study wildlife populations. A number of studies have reported using noninvasive sampling techniques to investigate population genetics and demography of wild populations ${ }^{1}$. This approach has proven to be especially useful when dealing with rare or elusive species ${ }^{2}$. While a number of these methods have been developed to sample hair, feces and other biological material from carnivores and medium-sized mammals, they have largely remained untested in elusive small mammals. In this video, we present a novel, inexpensive and noninvasive hair snare targeted at an elusive small mammal, the American pika (Ochotona princeps). We describe the general set-up of the hair snare, which consists of strips of packing tape arranged in a web-like fashion and placed along travelling routes in the pikas' habitat. We illustrate the efficiency of the snare at collecting a large quantity of hair that can then be collected and brought back to the lab. We then demonstrate the use of the DNA IQ system (Promega) to isolate DNA and showcase the utility of this method to amplify commonly used molecular markers including nuclear microsatellites, amplified fragment length polymorphisms (AFLPs), mitochondrial sequences (800bp) as well as a molecular sexing marker. Overall, we demonstrate the utility of this novel noninvasive hair snare as a sampling technique for wildlife population biologists. We anticipate that this approach will be applicable to a variety of small mammals, opening up areas of investigation within natural populations, while minimizing impact to study organisms.

\section{Video Link}

The video component of this article can be found at https://www.jove.com/video/2791/

Protocol

\section{Hair snare}

Prior to setting up a snare, an ideal location has to be determined within the pika habitat or talus slope. This includes hay piles, which are vegetation caches that the animals collect in late summer as well as fresh scats found at latrine sites. Strips of packing tape (10-50cm in length) are rolled up to provide a $360^{\circ}$ sticky surface and are arranged in a web-like manner to envelope the entrance to the pika's hay pile (Fig. 1) or latrine site. Depending on the configuration of the rocks, a piece of fishing line may be used to support the structure of the hair snare, but this is often not necessary when entrances are quite small $(<30 \mathrm{~cm}$ in diameter), a complete description of the use of fishing line can be found in Henry and Russello $(2010)^{3}$. Hair snares are checked as often as possible, and hair samples deposited on the tape (Fig. 2) are then collected and labeled. Once transported back to the lab, hairs are removed from the sticky tape using sterile forceps and transferred into cryogenic tubes and stored at $-20^{\circ} \mathrm{C}$ until further manipulation. Hair samples clustered together along a hair snare are considered to belong to a single individual, while samples clustered independently are assumed to belong to different individuals. In the latter case, the hair is then placed in different tubes. These assumptions can later be tested by way of DNA fingerprints and calculations of probability of identity based on microsatellite genotypic data.

\section{DNA extraction}

Since pika hair is very thin and contains a tiny root bulb, we have previously shown that a minimum of 25 hairs are required to obtain sufficient amounts of DNA for good quality downstream PCR amplification ${ }^{3}$. We used the DNA IQ system (Promega, Madison, WI, USA) and a slightly modified version of the manufacturer's instructions for DNA isolation from hair samples. Firstly, the hair sample is spun down in a microcentrifuge in order to avoid loss of hair while opening the tube. Then the incubation solution is prepared by mixing $80 \mu l$ of incubation solution with $10 \mu \mathrm{l}$ of DTT $(1 \mathrm{M})$ and $10 \mu \mathrm{l}$ of Proteinase $\mathrm{K}(18 \mathrm{ng} / \mathrm{ml})$ to result in a final concentration of $0.1 \mathrm{M}$ DTT and $1.8 \mathrm{ng} / \mathrm{ml}$ of Proteinase K. Incubation solution $(100 \mu \mathrm{l})$ is added to the sample and incubated at $56^{\circ} \mathrm{C}$ for 1 hour. In the meantime, the lysis solution is prepared by adding $1 \mu \mathrm{l}$ of $\mathrm{DTT}$ $(1 \mathrm{M})$ for every $100 \mu \mathrm{l}$ of lysis buffer, resulting in a final DTT concentration of $0.01 \mathrm{M}$. Prepared lysis solution $(200 \mu \mathrm{l})$ is then added to the sample, along with $7 \mu \mathrm{l}$ of DNA IQ resin, vortexed for 3 seconds at high speed and incubated at room temperature for 5 minutes. The sample is then vortexed for 2 seconds and inserted in the magnetic stand, where separation of magnetic beads from the solution occurs. The remaining solution 
is then aspirated and discarded, being careful not to disturb the pellet of magnetic resin. The sample is then treated with $100 \mu \mathrm{l}$ of the prepared lysis solution, vortexed and returned to the magnetic stand where separation occurs again. The lysis buffer is aspirated and discarded, and this step is repeated three times using a wash buffer $(100 \mu \mathrm{l})$. The sample is subsequently left to dry in the magnetic stand for 15 minutes. Once dry, $100 \mu$ of elution buffer is added to the sample and incubated at $65^{\circ} \mathrm{C}$ for 5 minutes. The sample is vortexed and inserted into the magnetic stand. The solution now containing the eluted DNA is then transferred to a $1.5 \mathrm{ml}$ Eppendorf tube and stored at $-20^{\circ} \mathrm{C}$ until further manipulations. DNA from liver samples was also extracted using the DNA IQ system and used as a positive control for PCR amplifications.

\section{PCR amplification}

The DNA obtained from our noninvasive hair snare and liver samples were then used to amplify a suite of commonly used molecular markers (microsatellite, AFLP, mitochondrial cytochrome B and ZFX/ZFY sexing marker). PCRs were performed using a Veriti thermal cycler (Applied Biosystems, Foster City, CA, USA) in a $25 \mu \mathrm{L}$ volume containing: $10-20 \mathrm{ng}$ DNA, $0.5 \mu \mathrm{M}$ of each primer, $10 \mathrm{mM}$ Tris- $\mathrm{HCl}$ (pH 8.3 ), $50 \mathrm{mM}$ $\mathrm{KCl}, 1.5 \mathrm{mM} \mathrm{MgCl}_{2}, 200 \mu \mathrm{M}$ dNTPs, $10 \mu$ bovine serum albumin (BSA; New England Biolabs, Ipswich, MA, USA) and $0.5 \mathrm{U}$ AmpliTaq Gold DNA polymerase (Applied Biosystems). Cycling parameters for the microsatellite loci were optimised using a touchdown cycling program $\left(10 \mathrm{~min}\right.$ at $95^{\circ} \mathrm{C}, 35$ cycles at $95^{\circ} \mathrm{C}$ for $30 \mathrm{~s}, 30 \mathrm{~s}$ annealing, and $45 \mathrm{~s}$ at $72^{\circ} \mathrm{C}$, followed by a final step at $72^{\circ} \mathrm{C}$ for $10 \mathrm{~min}$ ). The annealing temperature decreased by $1^{\circ} \mathrm{C}$ per cycle from 60 to $55^{\circ} \mathrm{C}$ until reaching the sixth cycle, at which point the 29 remaining cycles continued at $55^{\circ} \mathrm{C}$. Cycling parameters for the mitochondrial fragments were as described above but consisted of 35 cycles with an annealing temperature of $50^{\circ} \mathrm{C}$. Amplified Fragment Length Polymorphism was undertaken following the protocol for vertebrate genomes described by Bonin ${ }^{4}$. Lastly, molecular sexing was undertaken using the PCR-RFLP of ZFX/ZFY loci with Hinfl restriction enzyme digestion ${ }^{5}$. The PCR products from the microsatellite, AFLPs and cytochrome $B$ sequences were run onto a ABI 3130XL genetic analyser (Applied Biosystems), while digested ZFX/ZFX fragments were run alongside a 100 bp ladder (New England Biolabs) on a 3\% agarose gel containing 2.5\% SYBR Safe DNA gel stain (Invitrogen, Carlsbad, CA, USA) and visualised using a RED personal gel imaging system (Alpha Innotech, San Leandro, CA, USA). Microsatellite and AFLPs were visualized using Genemapper v3.7 (Applied Biosystems) and the mitochondrial DNA chromatogram was visualized using Sequencher v4.7 (Gene Code Corporation, Ann Harbour, MI, USA).

\section{Representative results}

The DNA extracted from hair samples obtained using our noninvasive snare were used to PCR amplify various type of molecular markers. As a basis for comparison, DNA extracted using liver samples was amplified alongside our hair samples. Nuclear microsatellite loci were successfully amplified for both hair and liver samples (Fig. 3). Although the intensity of the signal was greater when using the liver samples, this did not have an adverse effect on genotype scoring (Fig. 3). Similar results were achieved when using AFLPs (Fig. 4), mitochondrial DNA sequences (Fig. 5), and the ZFX/ZFY molecular sexing marker (Fig. 6).

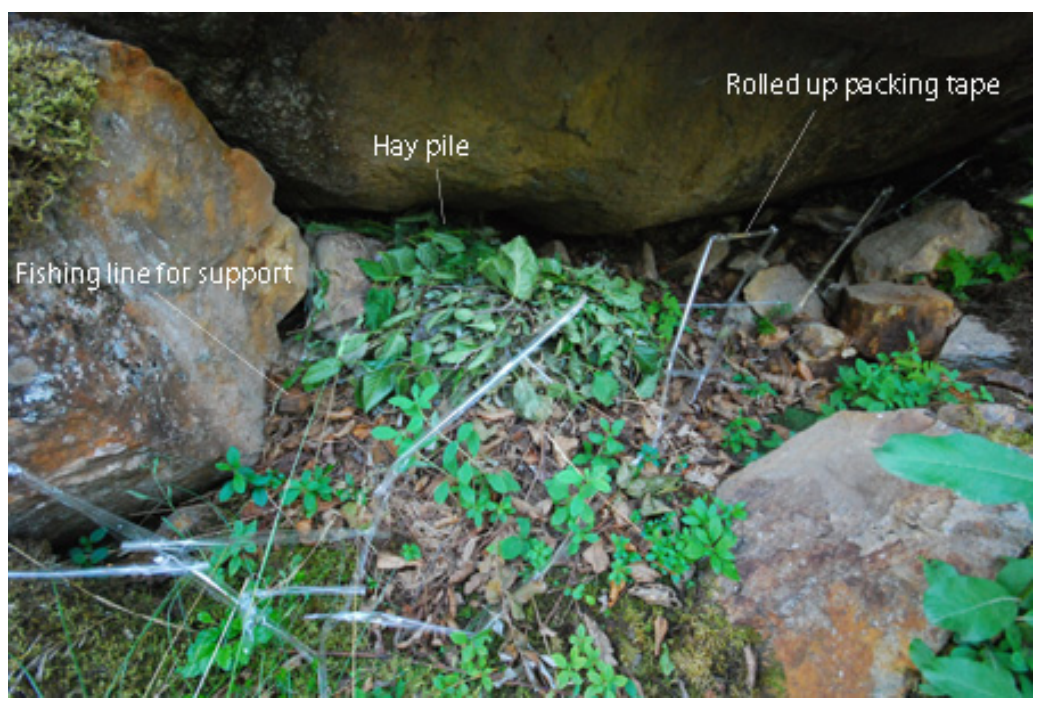

Figure 1. An example of a noninvasive hair snare set up at a hay pile. Strips of rolled up clear packing tape are arranged in a web-like fashion to enclose the entrance to the hay pile. A piece of fishing line is used here to provide additional support for the hair snare. 


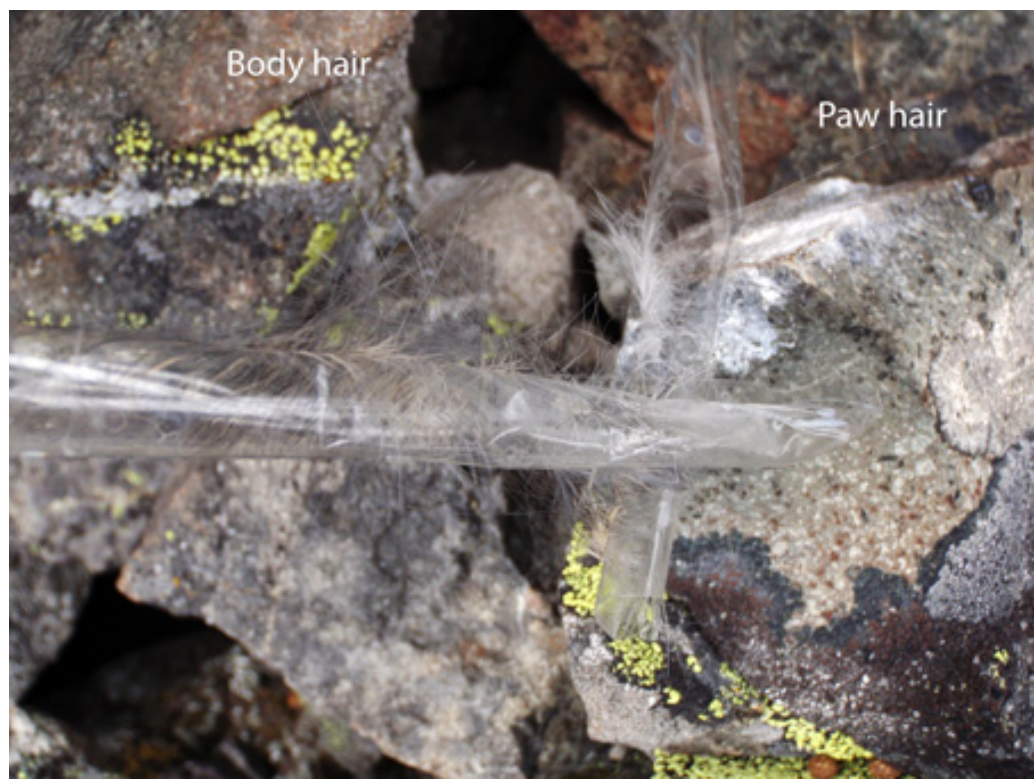

Figure 2. A successful hair snare containing a large number of hair stuck to the packing tape.

\section{NUCLEAR MICROSATELLITE}
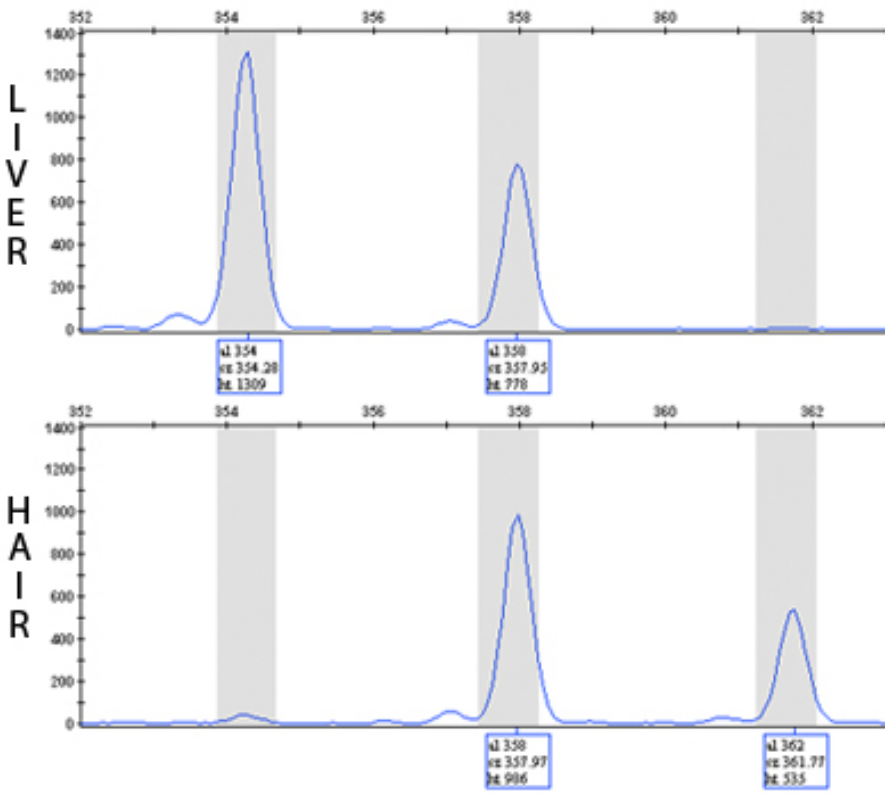

Figure 3. A representative nuclear microsatellite chromatogram $(\mathrm{Ocp} 6)^{8}$ as displayed in Genemapper v3.7 (Applied Biosystems). The top chromatogram was obtained by amplifying DNA from liver tissue, and is heterozygous (354/358) at this locus. The bottom chromatogram represents a different individual exhibiting a heterozygous genotype (358/362) based on DNA extracted from hair. While the signal of chromatogram from the hair sample has a lower intensity than the liver sample, genotype scoring is not adversely affected by this difference in signal. 


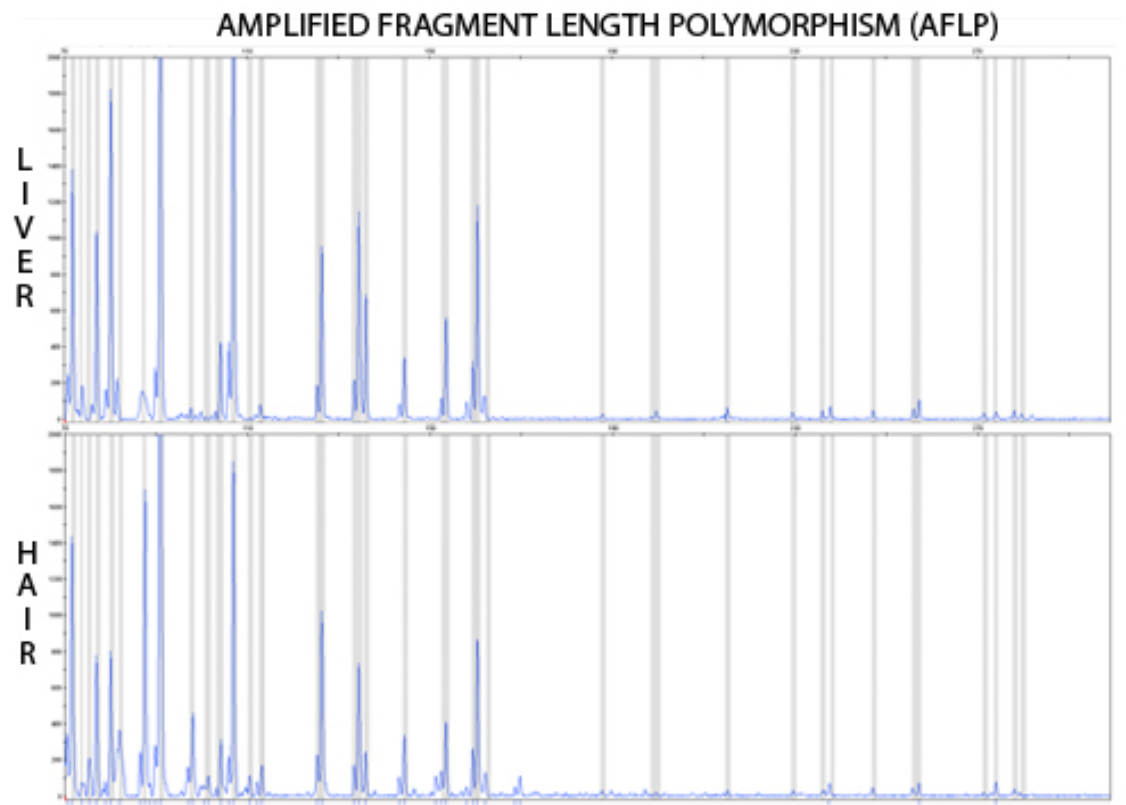

Figure 4. A representative AFLP chromatogram (E31T32) as displayed in Genemapper v3.7 (Applied Biosystems). The top chromatogram was obtained by amplifying DNA from liver tissue, the bottom chromatogram represents the DNA extracted from hair.

MITOCHONDRIAL DNA SEQUENCES (CYTOCHROME B)
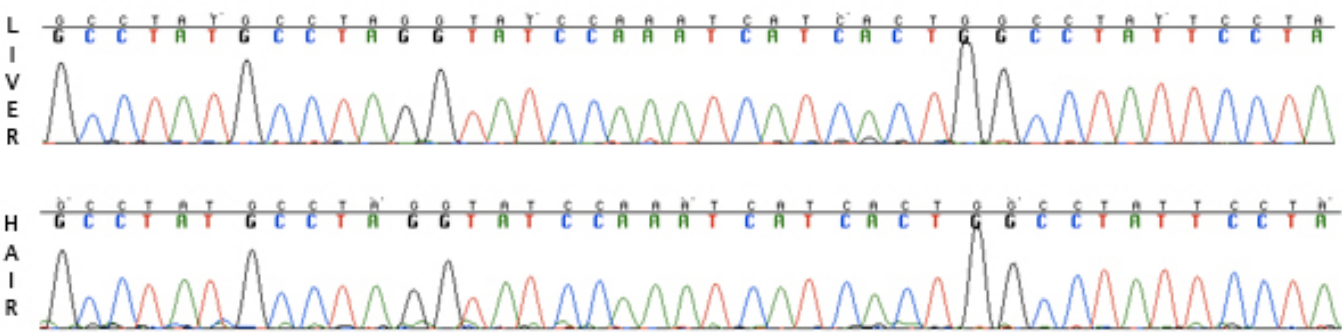

Figure 5. A representative mitochondrial DNA sequence chromatogram (cytochrome B) as displayed in Sequencher v4.7 (Gene Code Corporation). The top chromatogram was obtained by amplifying DNA from liver tissue, the bottom chromatogram represents the DNA extracted from hair.

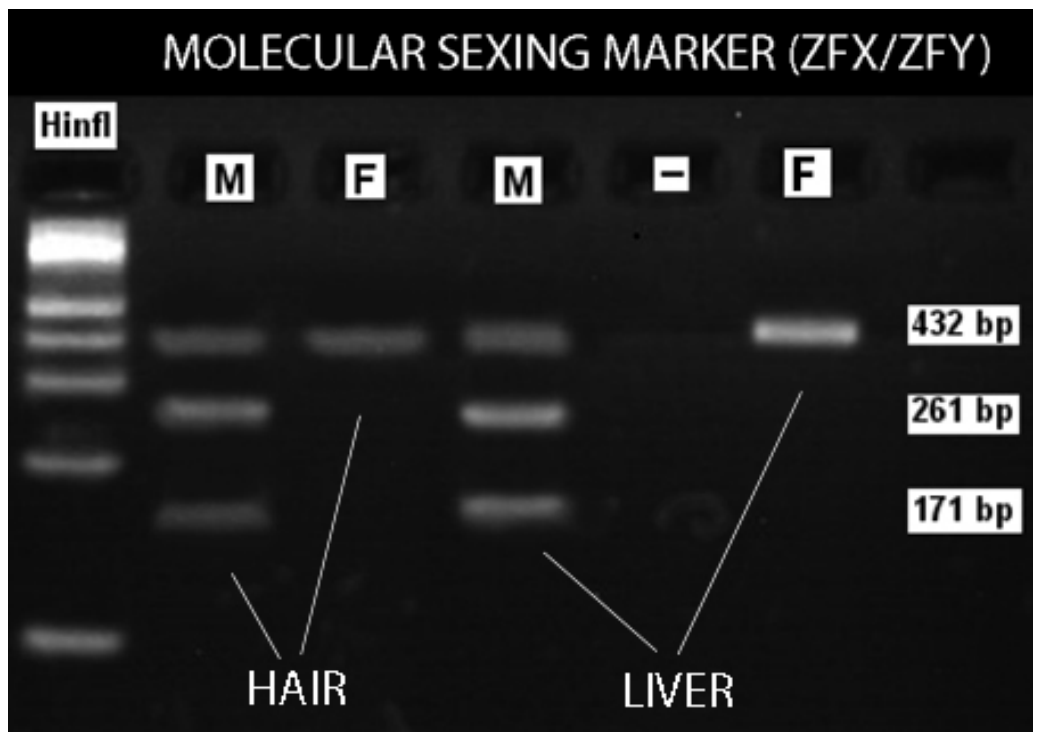


Figure 6. A representative molecular sexing marker (ZFX/ZFY) amplified for both liver and hair samples. This approach relies on the observation that the $\mathrm{Y}$ chromosome possesses a Hinfl restriction site in this region that the $\mathrm{X}$ chromosome lacks. Thus, females produce two co-migrating fragments of $432 \mathrm{bp}$ while males produce fragments of $432 \mathrm{bp}, 261 \mathrm{bp}$ and $171 \mathrm{bp}$.

\section{Discussion}

Noninvasive genetic sampling has become an attractive alternative to traditional live trapping methods for several reasons. First, by unobtrusively collecting biological material (e.g., feces, hairs, feathers, saliva and mucus) from wild populations, researchers can study these species without disturbing, handling, or even observing them, thus reducing risks to both animals and researchers. Second, noninvasive genetic sampling enables biologists to study populations of elusive and rare species, a task that can prove difficult with more traditional live-trapping approaches ${ }^{6}$. And third, NGS can potentially increase sample sizes by reducing disturbance to animals, sampling efforts, and costs, thus helping to minimise biases in estimates of population parameters ${ }^{7}$. This latter point may prove crucial when dealing with threatened species, since biased estimates of population parameters may result in inappropriate management.

In the present video article we describe a simple, novel, inexpensive and noninvasive method to sample elusive small mammals, using the American Pika as an example. We demonstrate that DNA extracted from hair performs similarly to DNA extracted from liver samples with respect to microsatellite, AFLP, mitochondrial and sexing markers, making this noninvasive sampling method an attractive alternative to live trapping or lethal sampling. Overall, we anticipate that this method will be useful in the data collection stage of population genetic and behavioural studies of rare or elusive small mammal species, while minimizing impact on the organisms under study.

\section{Disclosures}

No conflicts of interest declared.

\section{Acknowledgements}

We would like to thank L. Evans, B. Granger, D. Rissling, Z. Sim, A. Goodwin, K. Hayhurst and D. Kuch for assistance in the field. K. Galbreath kindly provided pika liver samples from the Bella Coola valley. Thanks to A. Gonçalves da Silva and K. Larsen for interesting discussions that contributed to the design of this noninvasive genetic sampling method. This work was funded by the Natural Sciences and Engineering Research Council of Canada Discovery, and UBC Okanagan Individual Research grants to MAR. A Swiss National Science Foundation Doctoral Fellowship PBSKP3_128523 supported PH. This study was undertaken following the animal care protocol from the University of British Columbia (Certificate number: A07-0126).

\section{References}

1. Kendall, K. C. et al., Demography and Genetic Structure of a Recovering Grizzly Bear Population. J Wildlife Manage 73 (1), 3 (2009); Rudnick, J. A., Katzner, T. E., Bragin, E. A., and DeWoody, J. A., A non-invasive genetic evaluation of population size, natal philopatry, and roosting behavior of non-breeding eastern imperial eagles (Aquila heliaca) in central Asia. Conserv. Genet. 9 (3), 667 (2008).

2. Henry, P. et al., In situ population structure and ex situ representation of the endangered Amur tiger. Mol Ecol 18 (15), 3173 (2009).

3. Henry, P. and Russello, M. A., Obtaining high quality DNA from elusive small mammals using low-tech hair snares. Eur $J$ Wildlife Res (2010).

4. Bonin, A., Pompanon, F., and Taberlet, P., Use of amplified fragment length polymorphism (AFLP) markers in surveys of vertebrate diversity. Method Enzymol 395, 145 (2005).

5. Fontanesi, L. et al., Sexing European rabbits (Oryctolagus cuniculus), European brown hares (Lepus europaeus) and mountain hares (Lepus timidus) with ZFX and ZFY loci. Mol Ecol Resour 8 (6), 1294 (2008).

6. Piggott, M. P. and Taylor, A. C., Remote collection of animal DNA and its applications in conservation management and understanding the population biology of rare and cryptic species. Wildl. Res. 30 (1), 1 (2003).

7. Banks, S. C. et al., Demographic monitoring of an entire species (the northern hairy-nosed wombat, Lasiorhinus krefftii) by genetic analysis of non-invasively collected material. Anim. Conserv. 6, 101 (2003); Litvaitis, J. A. et al., A range-wide survey to determine the current distribution of New England cottontails. Wildlife Soc B 34 (4), 1190 (2006).

8. Peacock, M. M., Kirchoff, V. S., and Merideth, S. J., Identification and characterization of nine polymorphic microsatellite loci in the North American pika, Ochotona princeps. Mol Ecol Notes 2 (3), 360 (2002). 